\title{
REFLEXIONES ONTOLÓGICAS SOBRE LA FILOSOFÍA APLICADA: LA PREGUNTA POR EL SER A PARTIR DE LA EXPERIENCIALIDAD EN LA CONSULTORÍA
}

\author{
ONTOLOGY MEDITATIONS AROUND PHILOSOPHICAL COUNSELING: \\ THE QUESTION ABOUT BEING FROM EXPERIENTIALITY IN \\ COUNSELING
}

\author{
JoSE LUIS CiSNEROS ARELLANO \\ Universidad Autónoma de Nuevo León \\ profr.cisneros@gmail.com
}

RECIBIDO: 7 DE AGOSTO DE 2017

ACEPTADO: 1 DE SEPTIEMBRE DE 2017

Resumen: El presente artículo tiene como objetivo mostrar cómo un replanteamiento de la ontología inherente al estoicismo, puede ajustar su cimiento ontológico como base para el esquema FALA y FAE de Barrientos Rastrojo. En primer lugar, plantearé algunas razones que justifican la pertinencia de atender el fondo ontológico del consultante, a partir de la noción de "cura filosófica" dentro de la práctica de la Filosofía Aplicada. En segundo lugar, señalaré cómo el estoicismo puede abonar en esa tarea, siempre y cuando se haga un replanteamiento ontológico de los géneros "dispuesto de cierto modo" y "dispuesto de cierto modo respecto a algo". En tercer lugar, mostraré cómo la perspectiva ontológica del Pensamiento Complejo puede contribuir a dicho ajuste del estoicismo, de tal forma que atienda a la noción de experiencialidad.

Palabras clave: Filosofía aplicada, ontología, cura filosófica, estoicismo, Pensamiento Complejo, experiencialidad.

\begin{abstract}
This article aims to show a rethinking of the ontology inherent to stoicism, in order to adjust its ontological foundations for FALA and FAE schemes of Barrientos Rastrojo's Philosophy. In first place, I will present some justify reasons of the relevance of look at the ontological background of the consultant. Specifically the notion of "philosophical cure" for a Philosophical counseling. Then, I will to show how stoicism can contribute to this task, with an ontological reformulation of his two types of genres: "disposed in a certain way"
\end{abstract}


and "disposed in a certain way about something." Finally, I will show how the ontological perspective of Complex Thought can contribute to this enterprise, for attends to the notion of experientiality.

Keywords: Philosophical counseling, ontology, philosophical cure, stoicism, Complex Thought, experientiality.

\section{Panorama general de la filosofía aplicada}

La Filosofía Aplicada se entiende como la puesta en marcha de los contenidos teóricos y experienciales que una persona lleva a cabo a partir de una actitud cuestionadora, racional y de apertura. Esta primera definición, groseramente simplificada, coloca en el centro de la atención algunos conceptos que merecen aclaración antes de dar paso a una definición más completa; para ello acudo a la propuesta por José Barrientos Rastrojo y en lugar de proceder como él hace, de su definición hacia la aclaración de sus conceptos, inicio con los conceptos para arribar a una definición.

Para Barrientos, la Filosofía Aplicada implica la noción de proceso, la cual señala un "ir hacia adelante" a partir del reconocimiento de un lugar o topoi que sirve de punto de referencia en torno al cual gira el pensamiento. En su Resolución de conflictos desde la filosofía aplicada y desde la mediación ${ }^{1}$, José Barrientos apunta que la filosofía aplicada es en primera instancia una actividad reflexivo-vital, jamás un estancamiento en el pensar ${ }^{2}$. Esta puesta en acción de la reflexión, emplea conceptos que son entendidos como bloques en la construcción del puente que permite transitar hacia diversos linderos y nuevas experiencias del pensar; los conceptos son las palabras que sintetizan los sentimientos, las ideas, las creencias, las dudas y las experiencias de la persona.

${ }^{1}$ BARRIENTOS, José: Resolución de conflictos desde la filosofía aplicada y desde la mediación. Manual formativo. Universidad Autónoma de Madrid, Madrid, 2012.

${ }^{2}$ BARRIENTOS, op. cit., pág. 160. 
Clarificarlos y definirlos con precisión forma parte la puesta en marcha de la Filosofía Aplicada a través del asesoramiento filosófico. A su vez, clarificar conduce a pensar que toda construcción se sentido implica hacer evidentes los vacíos o los contenidos de los propios actos de pensamiento y con ello, de los conceptos usados. Según Barrientos, clarificar conlleva una dosis de responsabilidad por el propio discurso, ya que es común, pero no regla, identificar "una falta de conciencia de la propia vida", que acentúa la relevancia de algunos episodios, ideas o creencias en el consultante, mismas que adquieren un aspecto central, como cuestiones relevantes cargadas de subjetividad. Todas ellas apuntan hacia lo que la persona es, ya que afectan directamente su identidad ${ }^{4}$, este concepto a su vez permitirá introducir más adelante el camino que conduzca hacia el cambio sustantivo del consultante. Esto último es importante porque saca a flote el fondo ontológico que angustia a la persona y que le invita a buscar la asesoría del filósofo. La premisa permite considerar que "el compromiso del filósofo es con el saber, a pesar de las consecuencias",; y no es que la advertencia sea el preludio de un estado incómodo negativo, la idea de fondo en realidad es la liberación de los prejuicios y la toma de decisión consciente; "a pesar de las consecuencias" implica que descubrir las verdades que gobiernan nuestros juicios podrían no ser del todo amables, o ligeras. El proceso de clarificación del pensamiento y por tanto, de evidenciar lo que la persona es según su propia libertad de reflexión y acción, no siempre conlleva la amabilidad de un despertar con la luz cálida y reconfortante del sol primaveral, pero sin duda consiste en un despertar que obligará a reconsiderar los lugares o topoi de los cuales partimos y desde los cuales somos.

\footnotetext{
${ }^{3}$ Ibid, 161

${ }^{4}$ Ibid, 162 .

${ }^{5}$ Ibidem.
} 
Tomar las riendas a pesar de la dificultad que ello ocasione terminará siendo la primera condición, tarde o temprano, de un ser o existir encaminado hacia el bien-estar. Concentrarse en el proceso reflexivo entonces, es primordial y se coloca como el principal objetivo del filósofo consultor, pues, sin la pretensión de ofrecer una terapia que busque la felicidad o la paz en el consultante, sí atiende los procesos gnoseológicos, lógico-argumentales y conceptuales $^{6}$ en general, haciéndolos explícitos y permitiendo con ello poner sobre la mesa de análisis las cartas abiertas a las que se enfrenta todo aquel que consulta con un filósofo aplicado. Con esta breve aproximación a las nociones centrales de la Filosofía Aplicada, es posible ahora acudir a una primera definición que aporta Barrientos Rastrojo; la Filosofía Aplicada es un

Proceso de conceptualización y/o clarificación acerca de cuestiones relevantes (significativas y/o esenciales) para el consultante donde el objetivo del orientador es la mejora del acto de pensamiento y/o depuración de sus contenidos veritativos y el resultado para el consultante acostumbra a ser su bien-estar. ${ }^{7}$

La última noción clave ahora es la de bien-estar, y se ha incluido en el listado previo de conceptos e ideas porque implica un punto de quiebre que dará pie a la siguiente sección. Entender la consultoría filosófica implica ir "más allá" a partir del análisis de un "más acá" que saque a flote el ser que se encuentra "entre" dichos allá y acá de la existencia. Allá, acá y entre son los ámbitos en los que descansa la palabra griega meta $(\mu \varepsilon \tau \alpha)^{8}$, aquella que se empleó para significar la meta-ta-physicá de Aristóteles por boca de Andrónico de Rodas, y que hace referencia directa hacia la filosofía primera, la ontología como pregunta por el ser del ente -en este

\footnotetext{
${ }^{6} \mathrm{Ibid}, 164$.

${ }^{7}$ Ibid, 158 .

${ }^{8}$ AA.VV., Diccionario Manual Griego-Español, Ed. Vox, Madrid, 1999.
} 
caso, la pregunta por el ser del ente humano que consulta- y no implicaría necesariamente, pero tampoco excluiría, la posibilidad de una realidad más allá de la physis.

El bien-estar del consultante apunta hacia su estructura fundamental, su dimensión ontológica; es ahí en donde se la consultoría filosófica se convierte en un auténtico eureka y punto de apoyo con el que se puede, parafraseando a Arquímedes, mover el mundo del consultante, su ser.

\section{La consultoría filosófica}

Nombrada también como orientación o asesoría filosófica, la consultoría hace énfasis en reflexión del consultante o cliente, guiado siempre por el filósofo aplicado o consultor. Esta guía suele ser considera en una primera aproximación por quienes no han escuchado antes sobre esta forma de aplicar la filosofía, como una terapia al modo de como hace un psicoanalista o un psiquiatra. Sin embargo, esta no es una opinión que se mantenga en los círculos de filósofos aplicados en virtud de las diferencias epistemológicas que salen a flote en las discusiones o debates académicos. Para algunos como Jon Mills, la solución al problema de si la consultoría o asesoría filosófica es o no una terapia, se soluciona a partir de considerarla como una práctica que puede servirse del paradigma "filo-psicológico" y sus técnicas ya que en esencial la asesoría filosófica forma parte de la psicoterapia, aunque la primera no la haya aceptado aún ${ }^{9}$. Mills considera que el filósofo aplicado no acepta la implicación psicológica que entraña el método por él propuesto, $y$, aunque "Achenbach is attempting to stay faithful to the Socratic method, although he diverts it from the Socratic

9 MILLS, Jon: "Philosophical Counseling as Psychotherapy: An Eclectic Approach", disponible on-line en http://npcassoc.org/docs/ijpp/mills.pdf (último acceso 10 de junio de 2017). 
pursuit of truth”"10, no obstante él insiste en que se Achenbach se suscribe

to an open and indeterminate process of dialectical questioning. While this is fruitful in some contexts and does deserve our close inspection with regards to method, it nevertheless denies the psychological and psychodynamic configurations that underlie the nature of any interpersonal process. Achenbach apparently thinks that philosophical discourse stands on the periphery of psychological forces, when it is an uncontested empirical fact that philosophical activity is psychologically embodied ${ }^{11}$

A pesar de que Mills entiende que los "philosophical counselors highlight the centrality of self- reflection, clarification of values, and delineation of a coherent world-view" "12, aún así considera que el paradigma psicológico ofrece las técnicas adecuadas para obtener un beneficio tangible para el consultante; y aunque esto podría estar en congruencia con el objetivo del asesoramiento como posibilidad de hacer cambios y lograr armonía según Peter Raabe ${ }^{13}$, no autoriza a implicar una relación necesaria, sino sólo suficiente. Si se entiende por filosofía a toda auto-reflexión que se proponga clarificar valores y conceptos, así como del mundo y de la vida a partir de un pensamiento racional, con dosis de actitud escéptica, son un ámbito o conjunto en el cual se encuentra el paradigma psicológico, se puede afirmar que usar dicho modelo es condición suficiente para pensar filosóficamente, pero esto no implica que sea condición necesaria ya que ambas se encuentran en una relación de implicación: se afirma $p$ entonces $q$, pero no es el caso que $q$ se dé para que $p$ sea efectiva.

En todo caso, el modo de pensamiento filosófico, en su afán por abarcar todos los ámbitos posibles, no ha concentrado toda la

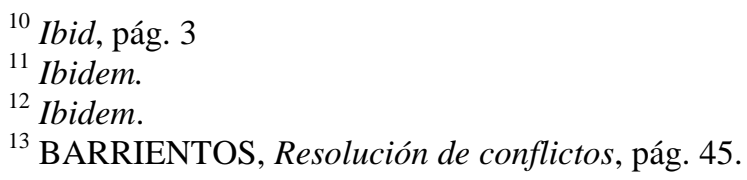


fuerza de su esquema o paradigma sobre el modo de ser que implica la psique, dando la oportunidad a que sean posibles algunas estrategias de intervención y análisis sobre ella, lo que ha dado lugar a la psicoterapia como una manera, ahora independiente en su ejercicio, del resto de la filosofía. Incluso aquellas estrategias implementadas por el psicoanálisis han surgido de médicos y psiquiatras que acuden a los marcos referenciales de la filosofía, por ejemplo Freud y su lectura de Brentano, así como Lacan y sus lecturas en torno a Heidegger.

Otra propuesta la tiene David H. Brendel, en el artículo Insight and Action: The Relation Between Professional Coaching and Philosophical Counseling ${ }^{14}$, de la cual se puede desprender como propuesta que la búsqueda del bien-estar que promueve el coaching, puede ser apoyado por las estrategias de pensamiento y los conceptos que la asesoría o consultoría filosófica ofrecen, pues parten del hecho de que cada paciente o consultante es capaz de ejercer con autonomía sus decisiones en virtud de la comprensión de su modo de ver el mundo y la vida, así como de sus propios prejuicios. Según Brendel,

Most coaches and philosophical counselors share the world-view that people possess a strong capacity for self-awareness, insight, choice, and responsibility. In contrast to the assumptions of mainstream psychiatrists, they tend to view people as fundamentally healthy and capable of selfunderstanding and effective action in the world. In his book Philosophical

\footnotetext{
${ }^{14}$ BRENDEL, David H., Insight and Action: The Relation Between Professional Coaching and Philosophical Counseling, disponible en http://web.b.ebscohost.com/abstract?direct=true \&profile=ehost\&scope=site \&aut htype $=$ crawler $\& \mathrm{jnnl}=17428181 \& \mathrm{AN}=97373075 \& \mathrm{~h}=\mathrm{PO} \% 2 \mathrm{ftXOBDzJcyT0TCZI}$ LuMvocrMYtQ38j6sRHulRtboDlDLmJ5Yz2FZQyhIbaAb5EiOJmYqTWRElvH VTkd\%2fvnUA\%3d\%3d\&crl=f\&resultNs=AdminWebAuth\&resultLocal=ErrCrl NotAuth\&crlhashurl=login.aspx $\% 3$ fdirect $\% 3$ dtrue $\% 26$ profile $\% 3$ dehost $\% 26$ scop e\%3dsite\%26authtype \%3dcrawler\%26jrnl\%3d17428181\%26AN\%3d97373075 (último acceso el 10 de junio de 2017).
} 
Practice, Lou Marinoff argued that most people's everyday problems "are best addressed by examining neither one's brain chemistry nor one's childhood traumas," but instead "by examining one's present intentions, volitions, desires, attachments, beliefs, and aspirations" (2002, p. xix). ${ }^{15}$

Aquí cabe bien una advertencia que hace Shlomit C. Schuster, sobre las nociones que tiene Marinoff sobre la psicoterapia y la psiquiatría. Seún Schuster, Marinoff se decanta hacia una comprensión poco informada y lejana del paradigma psiquiátrico, incluso llega afirmar que su intento por promover la contemplación y la espiritualidad de corte "asiático" y místico, no son propios de la filosofía como pensamiento crítico y analítico ${ }^{16}$. Con esto en mente y aunque en este trabajo se comparte la idea de que la filosofía no se distingue por su acercamiento a la mística, no es un ámbito por completo despreciable ya que algunos aspectos de ella pueden estar relacionados con lo que Barrientos llama "cuestiones relevantes (significativas y/o esenciales) para el consultante". A sabiendas de que filosofía no es exclusivamente oración y meditación, lo que el filósofo aplicado no debe perderse de vista, es que la consulta no significa dar $\operatorname{consejos}^{17}$, sino que, al tiempo que se privilegia la escucha y en conseguir que exista un cambio de ser en quien consulta, el resultado más probable será un bien-estar que supondrá en el común de los casos, un estado de felicidad plenamente consciente.

En ese sentido, se propone aquí como camino a explorar que la noción de "cura filosófica" puede ofrecer una carga significativa importante, pues es entendida en el sentido un "curador de arte" de museo y no como búsqueda de la salud o su restauración en el

${ }^{15}$ BRENDEL, Insight and Action, pág. 1366.

${ }^{16}$ SCHUSTER, Shlomit C., Marinoff's Therapy: A Critique of His Books on Philosophical Practice, disponible en http://npcassoc.org/docs/ijpp/SchusterMarinoff.pdf (último acceso el 10 de junio de 2017).

${ }^{17}$ BARRIENTOS, pág. 48. 
término médico. También se distinguiría sutilmente de la idea de "cuidado de sí" de Michael Foucault en el sentido de que ésta implica una práctica de libertad en el marco de las relaciones de poder $^{18} \mathrm{y}$, por tanto, de cuidado de $\operatorname{los}_{\text {otros }}{ }^{19}$, lo que conlleva a una ética y a entender a la libertad como fundamento ontológico de ella. La cura filosófica es un paso previo que en ocasiones requiere de la ayuda externa, entendida como condición para las prácticas de libertad con total toma de conciencia.

El filósofo aplicado contribuye entonces, a que las condiciones para que la reflexión se transforme en ejercicio autónomo de libertad, lo que permitiría hablar de una "cura" a través de los procesos y de los conceptos aplicando las dos grandes estrategias que propone Barrientos: FALA y FAE ${ }^{20}$. La "cura" no busca un estado de felicidad, sino un bien-estar. Ese bien-estar puede verse análogamente como el acomodo pertinente de las obras en un museo. Quien consulta puede entonces, encontrar un bien-estar en su ser que obedezca al orden o acomodo de las ideas que no le causen ni dudas, ni angustias. Siguiendo con la analogía, quizá alguna obra de su museo mental pueda parecer visiblemente perturbadora, pero esto no implica que deba ser retirada de la exposición; puede decirse que, así como el museo ofrece algunas obras trágicas, infelices y horroríficas, también la vida posee episodios trágicos, infelices y horroríficos, y no siempre felices o pacíficos.

\footnotetext{
${ }^{18}$ FOUCAULT, Michel, Estética, ética y hermenéutica, disponible en: http://exordio.qfb.umich.mx/archivos\%20PDF\%20de\%20trabajo\%20UMSNH/L IBROS\%2014/Foucault\%20Michel\%20-

$\% 20$ Estetica\%20Etica\%20Y\%20Hermeneutica\%20[Sicario\%20Infernal].PDF (último acceso el 10 de junio de 2017).

${ }^{19}$ Ibid, pág. 399.

${ }^{20}$ BARRIENTOS, José Introducción a la Filosofía Aplicada ACCI: Madrid, 2015.
} 
Antes de entrar de lleno al siguiente subapartado, considérese lo siguiente: la idea de que el consultante acude a la filosofía aplicada como apoyo para disolver (no solucionar) sus problemas, en virtud de que no ejerce su libertad éticamente hablando, podría suscitar una interpretación negativa. Todo lo contrario, pues se asume que el consultante tiene una moral que le guía en las decisiones cotidianas y en los horizontes de vida; incluso se acepta que lleva a cabo una reflexión moral lo suficientemente compleja y pertinente como para ser considerada una ética en su sentido más laxo, es decir, pre-filosófico. Sin embargo, cabe destacar que quien acude a una asesoría filosófica no es una persona ética en su sentido más filosófico. Es decir, no ejercer su libertad en función de un cuidado de sí, como diría Foucault, no se conoce a sí mismo socráticamente. Para pensar con ética y por tanto, hacerse cargo de su libertad, exigiría un modo de ser previo que le permitiera configurar su ser (en el sentido ontológico del término).

No pretendo ser exhaustivo en la siguiente idea porque no corresponde a los objetivos de este trabajo, pero tómese nota de lo que sigue. Pensar éticamente significa pensar con filosofía, no necesariamente como filósofo consagrado, sino a partir de los puntos de partida que convierten a todo pensar y a todo actuar, en una filosofía. Aquí se asume que filosofar implica el plan aristotélico de la filosofía primera hacia campos o ámbitos particulares de la realidad. Por ejemplo: la ética es preguntar por el ser de lo moral, la estética es preguntar por el ser de la belleza, la epistemología es preguntar por el ser de los criterios científicos de validez y veracidad. Preguntar por el ser implica un ejercicio constante de articulación entre los saberes especializados con la tradición filosófica $\mathrm{y}$, con el rigor propio de quien busca ser entendido y no mal interpretado. También implica buscar un fundamento que funja como principio rector de aquello por lo que preguntamos. En este sentido, la ética no adopta ningún canon de ideas, ninguna axiomática fundadora, ningún conjunto de criterios 
pre-establecidos; la ética adopta la actitud y las preguntas propias de todo filosofar y en ese sentido, no son impositivas, sino cuestionadoras. Pensar con ética es considerar a todos los factores que intervienen $\mathrm{y}$, con ello, proponer conceptos que permitan encapsular la complejidad de la postura asumida y de la decisión tomada. Sólo en estas condiciones estaríamos en la posibilidad de encontrar el ser de aquello por lo que pensamos éticamente.

Por tanto, la noción de "cura filosófica" está articulada con el filosofar pleno que el consultor filosófico puede motivar en el consultante. Para ello, el consultor, después de emplear las técnicas del FALA y del FAE, podrá hacer evidente el replanteamiento ontológico de los paradigmas que sirven de punto de apoyo para el consultante y, al hacerlo, contribuir a que el consultante ponga en marcha su pensamiento propio, es decir, su "cuidado de s'́".

La idea de que el FALA requiere de un complemento, según Barrientos, conduce a considerar la necesidad de poner en práctica lo analizado y explorado en las consultorías. Una opción teóricopráctica que la historia de la filosofía ha proporcionado es el estoicismo como filosofía del gnoothi seautón ( $\gamma v \tilde{\omega} \theta \imath$ $\sigma \varepsilon \alpha v \tau o ́ v)$ que Sócrates y otros griegos adoptaron como premisa de vida. En el siguiente apartado se abordarán algunas consideraciones ontológicas previas que buscan señalar la posibilidad de que el estoicismo griego y romano puedan ser vías de desarrollo para la propuesta de la experiencialidad.

\section{El fondo ontológico del estoicismo como estrategia de la filosofía aplicada}

El estoicismo nació con el chipriota Zenón de Citio a finales del siglo IV a. C. Sus inicios al pie de un pórtico de Atenas (stoa en griego) hicieron hincapié en la premisa de que cualquier cosa podía ser cuestionada, incluso las enseñanzas mismas de Zenón; esto nos 
permitirá hacer algunas afirmaciones fuertes más adelante. Si bien los aportes principales del estoicismo se hicieron en el terreno de la ética y de la lógica, también contribuyeron en el planteamiento ontológico a partir de un proto-panteismo y de la consideración de que todo se encuentra dentro de los límites de la physis entendida como materia, la cual se sujetaba a las reglas del mecanicismo absoluto. En virtud de ello, el estoico ha buscado trazar una ruta de abordaje de su vida, y de su relación con los otros, frente la abrazadora cosmología mecanicista que tiene por fundamento ontológico un criterio monista; este fundamento condiciona una visión ecológica de la realidad y una noción antropológica de vinculación permanente con ella y con el otro. Lo que permite a su vez, deducir las implicaciones ontológicas que subyacen. En lo que sigue, se abordará el aspecto ontológico del estoicismo y propondremos un replanteamiento del mismo, en virtud de que dicho cambio de paradigma hará posible una propuesta ontológica para la experiencialidad dentro de los límites de la consultoría filosófica.

\section{El estoicismo: replanteamiento de su fondo ontológico}

El planteamiento ontológico del estoicismo postula al concepto "algo" ( $t i)$ como la noción suprema de la realidad, en lugar de hacerlo con el concepto de ente (on) o el de ser (einai) que corresponden a la tradición platónico-aristotélica (y medieval). Ese algo se entiende como la forma en la que se puede concebir a la physis en su unidad mínima. Como noción, se divide a su vez en dos grandes géneros: lo corpóreo y lo incorpóreo. A su vez, los incorpóreos se subdividen en categorías genéricas que son: los lektá (decibles, el logos), el vacío, el espacio y el tiempo. Existen dos géneros de lo corpóreo que son lo "dispuesto de cierto modo" o de cierta manera- y lo "dispuesto de cierto modo respecto a algo" $-\mathrm{o}$ en orden a algo--. En lo que sigue mostraré que éstas últimas dos 
afectan directamente la forma en cómo se relacionan los lektá con la manera de construir una postura ética y las acciones que ello conlleva.

Según Marcerlo D. Boeri en su artículo Ser y géneros del ser en el estoicismo antiguo, los estoicos replantean las estructuras categoriales propuestas por Platón y Aristóteles respecto al ser para solventar las dificultades que implica concebir que el alma posee una naturaleza distinta de la del cuerpo y con ello, señalar la correspondencia entre cambios en el alma y cambios en el cuerpo con implicaciones éticas explícitas ${ }^{21}$. El punto central de su discusión radica en que los géneros llamados "dispuesto de cierto modo" y "dispuesto de cierto modo respecto a algo" permiten explicar cómo los lektá influyen directamente sobre la postura ética y sobre el comportamiento. Boeri señala dos ejemplos: "conocimiento" y "puño". Desde el punto de vista de lo "dispuesto de cierto modo" -que es el llamado tercer género en la filosofía estoica, mientras que los dos primeros géneros son el sustrato y lo cualificado-, tanto el conocimiento como el puño son "determinaciones de algo determinado, a saber, el individuo cualificado que llamamos 'alma' y 'mano' respectivamente",22. Si se piensa en que tanto conocimiento como puño se pueden entender como predicados, se puede deducir que tanto alma como mano no cambian por un factor externo que modifique su "modo" de estar dispuesto; i.e. el alma no deja de ser alma si se encuentra en estado de ignorancia o de conocimiento, y lo mismo con la mano, pues no dejará de ser mano si está dispuesta de modo cerrado (puño) o

${ }^{21}$ BOERI, Marcelo D., "Ser y géneros del ser en el estoicismo antiguo. Una distinción ontológica importante aplicada a la ética y la teoría de la acción". Pensamiento, vol. 66, núm. 247, Madrid, 2010, pp. 55-81.

${ }^{22} \mathrm{Ibid}$, pág. 67. 
abierta $^{23}$. Esto implica que estar "dispuesto de cierto modo" no es un incorpóreo, sino el modo en que se cualifica algo ${ }^{24}$.

Respecto a lo "dispuesto de cierto modo respecto a algo" -qué es el cuarto género-, Boeri señala que se trata de entender que el "ser es lo que es solamente respecto de otra cosa" 25 como el caso de la amistad según el ejemplo de Estobeo que cita Boeri. Esto también podría decirse de la mano, la cual es mano respecto a algo más, que para el caso es el resto del cuerpo. Este cuarto género brinda la posibilidad de relacionar los primeros tres géneros con los lektá porque, sin dejar de ser corporal, este tipo de género del ser es un factor extrínseco que sí modifica el estado de la situación y que terminará siendo oikeiosis, es decir, una postura ecológica de relación no sólo con uno mismo y el entorno, sino con los otros; esto implica básicamente que reconocer el grado de enlace físico (physis) que todos los ti (algo) poseen y permite, de nuevo, reconocer un sentido de pertenencia, exón, -Boeri lo traduce como "manera" o "modo" del tercero y del cuarto géneros del ser-, empezando con el ser que somos y culminando con los seres que nos rodean ${ }^{26}$. Entendido como un agente externo relativo (de relación con otros), el cuarto género afecta directamente a los lektá porque estos se conciben como simbolizaciones y "en cuanto signos son físicos (son parte del logos y como él, son físicos; DL VII 58)"27. Lo que conduce directamente al enlace entre el giro

${ }^{23}$ Ibidem.

${ }^{24}$ Ibid, pág. 70.

${ }^{25}$ Ibid, pág. 73.

${ }^{26}$ Si se entiende que, lo "dispuesto de cierto modo" -o de cierta manera- y lo "dispuesto de cierto modo respecto a algo" -o en orden a algo-, implican una función o propiedad que los distingue y que les permite ser de "ese modo" y "respecto a algo", entonces se puede deducir que también implica una la relación a un conjunto que alberga esa propiedad o "modo de estar dispuesto" para el tercer género $\mathrm{y}$, una relación respecto a otro conjunto con otro "modo de estar dispuesto".

${ }^{27}$ BOERI, Op. cit., pág. 56. 
ontológico de los estoicos (respecto a Platón y Aristóteles) y su propuesta ética.

El sujeto, una vez verificada la correspondencia entre el cuerpo y el lektá, presta atención en la intención o acción, pues el alma moverá al cuerpo en virtud de algún factor externo. Ahora bien, debe aclararse que

La facultad que hace posible tal mediación es la que los estoicos denominan «asentimiento» (sygkatãthesioo), que consiste en una toma de posición, a través de la cual se da por verdadera la proposición que articula el contenido de la correspondiente presentación (o la presentación en sí que ya es una proposición) [...] Si el asentimiento consiste en dar por verdadera la proposición (que es la presentación), entonces tendrá la forma del acto de afirmar la pertenencia de un predicado al sujeto de la proposición. ${ }^{28}$ Cuando la acción es descrita con referencia a la intención del agente, entonces es el sujeto implicado el más apto para dar fe de ella y, en consecuencia, adoptar una postura ética y una acción correspondiente, precisamente porque la intensión del agente permite afirmar una proposición (lektá) deóntica -"debo hacer esto", "es correcto hacer esto otro"- que señala la dirección hacia la que se debe actuar. Pero he aquí un cuestionamiento que obliga a buscar un replanteamiento ontológico en aras de proponer una cimentación antropológica que permita vislumbrar un enfoque de experiencialidad para la consultoría filosófica, y es el siguiente: la puesta en marcha del enfoque ontológico, tal y como entendían la physis los estoicos, no ofrece la posibilidad de existencia de lo emergente ni de lo complejo - en el sentido que le da a ambas nociones el francés Edgar Morin- y por consiguiente, la conocida tesis de que el ser humano es libre sólo en su decisión de cómo asumir su pensamiento respecto a los sucesos físicos de los cuales no puede escapar ni los puede modificar; es decir, la famosa actitud

${ }^{28}$ Ibid, pág. 75. 
estoica de inmutabilidad ante las desgracias sufridas es imperativa porque los cuerpos y sus relaciones, están tan estrechamente relacionados que es imposible ser libre ante ellos, únicamente puede ser libre un pensamiento que acepte esta inevitabilidad y que actúe conforme a la virtud del conocimiento verdadero. En lo que sigue, abordaré la última sección de este artículo con el fin de mostrar cómo la ontología estoica replanteada con una dosis de pensamiento complejo, puede ser de utilidad para la puesta en marcha del FAE.

\section{Estoicismo reformulado como consultoría para la experiencialidad}

En este artículo creemos que la postura ontológica del pensamiento complejo permite replantear la propuesta ontológica de los estoicos sin romperla, y garantizar al mismo tiempo, la introducción de la libertad humana sin restringirla. En lo que sigue acudiré a las razones que considero pertinentes para dar ese ajuste al giro ontológico.

Según Edgar Morin, la interdependencia es una noción que ayuda a entender la relación que se presenta entre el entorno físico y el cognoscitivo, pues indica que la realidad que rodea a todo sujeto no es independiente de él; el Pensamiento Complejo acepta la idea de que la presencia del sujeto altera significativamente el modo en como se organiza la realidad. Esto es así porque, en su opinión, "para que haya organización es preciso que haya interacciones: para que haya interacciones es preciso que haya encuentros, para que haya encuentros, es preciso que haya desorden (agitación, turbulencia)" ${ }^{\prime 29}$. Ontológicamente esta idea significa interacción, misma que ayuda a comprender el cimiento físico de lo más elemental de la naturaleza, de la physis en sentido griego, a saber,

\footnotetext{
${ }^{29}$ MORIN, Edgar, El método I: La naturaleza de la naturaleza, tr. Ana Sánchez, Cathedra: Madrid, 2001, pág. 69.
} 
"el orden, el desorden, la potencialidad organizadora deben pensarse en conjunto, a la vez en sus caracteres antagonistas bien conocidos y sus caracteres complementarios desconocidos. Estos términos se remiten uno a otro y forman como un bucle en movimiento" 30 .

El fondo ontológico que mueve toda la realidad se hace presente no sólo a nivel elemental, sino también a nivel macro, lo cual incluye al sujeto. Desde dicho fondo, el desorden, el orden y la organización se organizan en bucle, incluso al nivel de las partículas elementales, Morin lo explica así:

Las partículas [...] ya no pueden ser consideradas como objetos elementales claramente defendibles, identificables, medibles. La partícula pierde los atributos más seguros del orden de las cosas y de las cosas del orden [...] Su sustancia se disuelve [...] en evento aleatorio. Ya no tiene localización fija e inequívoca en el tiempo y en el espacio ${ }^{31}$.

Esto es un replanteamiento al sustento monista de la physis tal y como la entendían los estoicos y como se puede empezar a notar, se requiere de un principio de complejidad, mismo que no implica la permutación de un término ontológico fundador en otro término fundador. Lo que Morin propone, es que se requiere de una noción compleja que no desprecie ninguna condición, ninguna relación, ningún antagonismo, e incluso ninguna paradoja debe quedar fuera del sistema general, el cual, apenas se empieza a reconocer en su diversidad. Ello implica pensarlo como

unitas multiplex (Angyal, 1941), es decir, paradoja: considerado bajo el ángulo del Todo, es uno y homogéneo; considerado bajo el ángulo de los constituyentes, es diverso y heterogéneo $[\ldots]$ no podemos reducir ni el todo

${ }^{30}$ Ibid, pág. 63.

${ }^{31}$ Ibid, pág. 55. 
a las partes, ni las partes al todo, ni lo uno a lo múltiple, ni lo múltiple a lo uno $^{32}$

Ahora bien, en el centro de toda esa complejidad, hace falta considerar un elemento, uno que aporte más indeterminación a toda esa interacción en donde el orden y el desorden generan a su vez organización. Es necesario porque ese bucle tiene características de dialéctica hegeliana y daría la impresión de que la organización es la síntesis de orden y desorden. La dinámica no es tan simple ya que implica la presencia de la emergencia, es decir, del brote inesperado, aparición inesperada, acontecimiento que sorprende por ser algo radicalmente nuevo.

Se puede llamar emergencias a la cualidades o propiedades de un sistema que presentan un carácter de novedad con relación a las cualidades y propiedades de los componentes considerados aisladamente o dispuestos de forma diferente en otro tipo de sistema $^{33}$.

Pero esto, en lugar de solucionar las dificultades de interpretación que podrían surgir frente a un sistema que combina bucles de interacción en todos sus niveles y que, en una primera mirada es confuso, introduce otro elemento complejo que terminará por explicar la afirmación de que, el sujeto sí modifica la realidad en la que se ve circunscrito. Dicho elemento es el siguiente, la noción de seres "en sí" que para Morin significa sistemas que se producen a sí mismos, como máquinas que en su dinámica son poiéticos, se autoproducen $^{34}$. Las nociones de bucle y apertura son centrales para entender esto, pues ello invita a concebir que la "producción-de-sí significa proceso retroactivo/recursivo" "35. Que, en otras palabras, significa entender que toda la realidad se encuentra en un proceso

\footnotetext{
${ }^{32}$ Ibid, pág. 128.

${ }^{33}$ Ibid, pág. 129.

${ }^{34}$ Ibid, pág. 211.

${ }^{35}$ Ibid, pág. 217.
} 
de creación constante y en ese sentido, no es totalmente mecánica, sino mecánica y no mecánica al mismo tiempo. A partir de ese panorama, Morin propone, siguiendo el esquema ontológico de la physis, que el ser humano debe ser entendido a partir del hecho de que la sola presencia de lo humano hace posible nuevas condiciones de interacción y que la influencia sobre la physis que terminarán por modificarla. La noción de auto-eco-organización será entonces central, pues implica la "organización de las interacciones internas y la organización de las interacciones externas" 36 , pues "todos los sistemas vivos son ecodependientes pero es en esta dependencia donde se da la autonomía"37. La propuesta de entender la relación del desorden, el orden, la organización y la emergencia en bucle, todas ellas en total apertura, además con la presencia de un sujeto, invita a aceptar que

Las verdades de lo existente son siempre incompletas, mutiladas, inciertas, puesto que dependen de más allá de sus fronteras. Cuanto más autónomo se hace lo existente, más descubre su insuficiencia, más busca los más allá. Y es esto lo que está en el origen de la necesidad, de la inquietud, de la búsqueda, del deseo, del amor ${ }^{38}$. Sin embargo, esto sería un problema si se busca incorporar la ontología del pensamiento complejo a la ontología estoica; me refiero a que la filosofía estoica deja en claro que el poder de influencia que el sujeto tiene sobre el mundo corpóreo es nulo, o casi nulo, de tal manera que la verdadera libertad y autonomía reside en la mente, en la capacidad racional. Las máximas de Epicteto, en su Enquiridión viene a señalar con claridad el punto que quiero mostrar aquí

De lo que existe, unas cosas dependen de nosotros, otras no. De nosotros dependen; el juicio, impulso, deseo, aversión y, en una palabra, cuantas son

\footnotetext{
${ }^{36}$ Ibid, pág. 235.

${ }^{37}$ Ibid, pág. 236.

${ }^{38} \mathrm{Ibid}$, pág. 239.
} 
nuestras propias acciones, mientras que no dependen de nosotros el cuerpo, la riqueza, honras, puesto de mando $\mathrm{y}$, en una palabra, todo cuando no son nuestras propias acciones ${ }^{39}$

Para los estoicos no hay confusión, la influencia que el ser humano ejerce sobre los entes corpóreos no es significativa y enfocarse en ellos implica esclavizarse a condiciones que no dependen del ser humano. La problemática es entonces manifiesta, plantear la ontología del pensamiento complejo ofrece la dificultad de conciliarse con esto. Para superarlo propongo la siguiente "máxima", a manera de paráfrasis de Epicteto: las cosas pueden depender de nosotros en la medida en la que los lektá que las enuncian, se encuentran en correspondencia compleja, es decir, en bucle con nosotros. Ello implica nuestro estado interno -“el juicio, impulso, deseo, aversión y, en una palabra, cuantas son nuestras propias acciones"-, además de algunos aspectos externos de nuestro cuerpo, de nuestros bienes y de nuestra palabra respecto a otras personas. Por otro lado, "no dependen de nosotros [como la complejidad inherente a todo cuerpo, así como] la riqueza, honras, puesto de mando y, en una palabra, todo cuanto no son nuestras propias acciones" en cuanto que no están interrelacionadas con nosotros.

Es decir, lo único en lo que la influencia humana no es significativa, es en la complejidad misma de la realidad. El rango de interacción en el que todo ser humano se vincula con su contexto varía en función de la complejidad del mismo y la reflexión estoica inicia por una ontología fisicalista y logicista que permite identificar ese grado de interacción entre la persona y su entorno. La consultoría filosófica, según FALA se concentra en primer lugar, en la escucha y la puesta en perspectiva de las circunstancias del consultante (que para el consultor filosófico

39 EPICTETO, Enquiridión, tr. José Manuel García de la Mora, Anthropos, Barcelona, 2004. 
equivale a una ontología fisicalista), seguido de un análisis de los conceptos y del discurso (ontología logicista). La puesta en marcha de la FAE se remite entonces hacia el ejercicio de las máximas estoicas que el consultor filosófico puede ir dosificando al consultante con el fin de propiciar una experiencialidad pertiente a la problemática en cuestión y ocasionar en él, un cambio en el ser que la persona es.

Asumir el estoicismo con una base ontológica anclada en la physis no se apartaría de la visión del pensamiento complejo, ya que el giro ontológico que podría desprenderse de él pone el acento justo sobre los géneros del ser que también asume el estoicismo. La noción de interacción y de bucle coincide con el tercero y el cuarto género del ser según los estoicos - "dispuesto de cierto modo" y "dispuesto de cierto modo respecto a algo"-, ya que tanto la interacción como la noción de bucle con relaciones de modo y respecto a algo. El bucle desorden-orden-organizacióndesorden... es una disposición de cierto modo, y estas son a su vez, siempre respecto a algo, que puede ser o incluso un emergente que es siempre "...respecto a algo". La adaptación a la ontología estoica haría posible que concibiera a la libertad fuera no sólo a nivel interno, propio de la propuesta estoica, sino a nivel de la correlación con el contexto y de esta forma, plantear en la consultoría filosófica la posibilidad de que las estrategias del estoicismo no impliquen una indiferencia por las circunstancias que configuran a la persona. Pero la coincidencia entre ambas ontologías no acaba aquí, Morin acepta que la realidad cultural corresponde a un grado de la physis, lo "decible", que coincide con el lektá estoico, y acentúa la posibilidad de que el ámbito de los "algo" que son "decibles", influyan sobre las relaciones que se presentan en los "algo" corpóreos (entes). De tal manera que las dos grandes divisiones de lo corpóreo y lo incorpóreo, tanto para la ontología estoica como para la compleja y, de paso, a una antropología y una ética. 
Boeri señala respecto de los alcances de la ontología estoica, que "la distinción de los géneros del ser, se aplica a la ética y la teoría de la acción estoicas" ${ }^{\prime 4}$, lo cual pienso se relaciona directamente sobre la experiencialidad según la FAE. Además, en virtud de que ninguna cosa es "por sí", sino que todas son respecto de algo, la condición compleja del ser humano lo vincula con ese "respecto a algo" que es su contexto, por ello aquí se ha propuesto que hacer ontología es indagar sobre el ser de algo, lo cual significa encontrar las relaciones que lo hacen posible y con ello, la posibilidad de que la persona que consulta pueda replicar algunas de esas condiciones que hagan posible modificar su propio ser y diluir el problema que lo aqueja.

Esta vinculación del ser humano con el contexto complejo conduce irremediablemente a una postura antropológica cuya primera tarea, es negar la premisa estoica de que el ser humano no es libre. En el fondo, la libertad estoica es quizá la mayor de todas porque supone un acto de aceptación sobre lo externo aún y cuando la voluntad deseara revelarse. No se trata de una condición ontológica de elección frente a un abanico de oportunidades, sino de tomar pleno control sobre las emociones y no sujetarse a ellas, liberarse de ellas; pero a un alto costo, aquel que pide no emprender una lucha contra las condiciones materiales a fin de doblegarlas. Esto convierte a la antropología para la postura estoica en un modo de relación estrictamente moral y en virtud de la cultura griega de aquellos tiempos, una vinculación directa con un pensamiento y una práctica religiosa como código de conducta, es decir, aceptar la existencia de los dioses.

No vivimos en sus tiempos y aunque las creencias religiosas pueden ser muy variadas en estos días, una consultoría filosófica no puede acudir al pensamiento religioso como único modelo moral que conduzca la reflexión ética o política. La postura antropológica

${ }^{40}$ BOERI, op. cit., pág. 67. 
puede adaptarse a la visión replanteada de la ontología estoica que aquí se ha puesto a consideración, y asumir, en primer lugar, que a mayor nivel de interacción con otros entes, mayor será la posibilidad de hacer efectiva su libertad de elección; el ejercicio de la reflexión filosófica es ya un paso en este camino e implicará necesariamente el libre cuestionamiento. Todo consultante puede poner en práctica esta libertad de cuestionamiento, en especial sobre sus propios esquemas de creencias establecidas, sobre sus construcciones teóricas, hipótesis e ideas que norman sus actos cotidianos. El consultante acude al filósofo aplicado porque piensa que puede salir de un problema que le aqueja o de un dilema que le impide elegir un camino; esta situación tan simple de entender, implica entonces una reconceptualización antropológica de lo que el consultante es, y aquí se ha venido creyendo que esta tarea parte desde la ontología.

De momento, la antropología debe reconsiderar que el ser humano es un ser corporal en comunión intrínseca con la naturaleza. Esta comunión es, sobre todo, ontológicamente compleja, poniendo especial atención en los géneros tercero -"dispuesto de cierto modo"- y cuarto -"dispuesto de cierto modo respecto a algo"-; que es un ser abierto/cerrado, que no puede existir sin protegerse y por tanto inspirado a cerrarse, pero obligado también a abrirse a otros, que le proporcionan lo necesario para seguir existiendo; y que es un ser que logra mayor autonomía en la medida en que depende, como una inmensa red de interacciones, de más factores, ya que ninguno se plantea como indispensable.

Así entendido, se abre un camino que puede servir de puente entre la ontología y la Filosofía Aplicada. En lo que sigue, algunas reflexiones finales a modo de conclusiones provisionales permitirán cerrar el argumento y dar paso al debate. 


\section{Conclusiones}

A lo largo de este artículo se ha abordado un breve panorama sobre la filosofía aplicada, en la cual se planteó que ésta puede derivar en una consultoría filosófica que, en lugar de depender de una práctica disciplinaria en particular, como lo puede ser el psicoanálisis, depende del reflexionar mismo de la filosofía como ejercicio socrático. Este camino, el de una noción de consultoría filosófica como tarea de diálogo constante, posee sus propias virtudes analíticas, en particular aquellas condensadas en FALA y complementadas en la FAE. Sin embargo, esta última estrategia, como apoyo a la primera, puede ser adoptada desde un punto muy particular de reflexión filosófica, a saber, el estoico. En artículo entonces, se concentró en un fondo ontológico estoico, el cual polemiza con la tradición ontológica que se desprende de Platón y de Aristóteles, y tiende un puente de vinculación con el pensamiento complejo de Edgar Morin que autoriza a replantear el cimiento ontológico mismo. Este replanteamiento nos condujo hacia una vinculación ética y política que asume, de entrada, la posibilidad de aplicar las técnicas estoicas para lograr una experiencialidad en la consulta filosófica y con ello, dar con el problema desde sus raíces ontológicas, esto es, con el ser del consultante. Al final, se propuso una forma de entender la consultoría filosófica que, al retomar el estoicismo reformulado, hace evidente la necesidad de replantear la postura antropológica de esta filosofía, y encaminarla hacia una más compleja.

Por último, lo que fundamentalmente se trata aquí, es de señalar que el punto de partida de todo reflexionar filosófico - que el consultor filosófico buscará motivar en el consultante- consiste en hacer preguntas por el ser de algo, y que las respuestas que vaya encontrando, le indicarán el modo en el que "está dispuesto" aquello por lo que preguntamos. Esta pregunta es metafísica y las respuestas son ontológicas; un cimiento ontológico claro y 
consistente, permitirá no sólo al consultante, sino también al consultor, encontrar las implicaciones gnoseológicas, lógicas, estéticas, éticas, axiológicas, epistemológicas y políticas que se puedan desprender de quien consulta.

\section{Bibliografía}

AAVV, Diccionario Manual, Griego-Español, Ed. Vox, Madrid, 1999.

BADIOU, Alain, Manifiesto por la filosofía, Nueva Visión: Buenos Aires, 1989.

BARRIENTOS, José: Resolución de conflictos desde la filosofía aplicada y desde la mediación. Manual formativo. Universidad Autónoma de Madrid, Madrid, 2012.

BARRIENTOS, José; PACKTER, Lucio; De CARVALHO, José Mauricio: Introducción a la filosofía aplicada y a la filosofía clínica. ACCI: Madrid, 2014.

BARRIENTOS, José Introducción a la Filosofía Aplicada ACCI: Madrid, 2015.

BOERI, Marcelo D., "Ser y géneros del ser en el estoicismo antiguo. Una distinción ontológica importante aplicada a la ética y la teoría de la acción". Pensamiento, vol. 66, núm. 247, Madrid, 2010, pp. 55-81.

BRENDEL, David H., Insight and Action: The Relation Between Professional Coaching and Philosophical Counseling, disponible en

http://web.b.ebscohost.com/abstract?direct=true \&profile=ehost \&sc ope $=$ site $\&$ authtype $=$ crawler $\&$ jrnl $=17428181 \& A N=97373075 \& \mathrm{~h}=\mathrm{P}$ O\%2ftXOBDzJcyT0TCZILuMvocrMYtQ38j6sRHulRtboDIDLmJ 5Yz2FZQyhIbaAb5EiOJmYqTWRElvHVTkd\%2fvnUA\%3d\%3d $\& \mathrm{crl}=\mathrm{f} \&$ resultNs $=$ AdminWebAuth\&resultLocal=ErrCrlNotAuth\& crlhashurl=login.aspx $\% 3$ fdirect $\% 3 \mathrm{dtrue} \% 26$ profile $\% 3$ dehost $\% 26 \mathrm{sc}$ 
ope \%3dsite\%26authtype\%3dcrawler\%26jrnl\%3d17428181\%26AN $\% 3 d 97373075$ (último acceso el 10 de junio de 2017).

CASTORIADIS, Cornelius, Le monde morcelé: Les carrefours du labyrinthe 3, Éditions du Seuil, Paris, 1990.

CASTORIADIS, Cornelius, Sujeto y Verdad en el mundo histórico social, FCE: México, 2004.

EPICTETO, Enquiridión, tr. José Manuel García de la Mora, Anthropos, Barcelona, 2004.

FOUCAULT, Michel, Estética, ética y hermenéutica, disponible en:

http://exordio.qfb.umich.mx/archivos\%20PDF\%20de\%20trabajo\% 20UMSNH/LIBROS\%2014/Foucault\%20Michel\%20-

$\%$ 20Estetica\%20Etica\%20Y\%20Hermeneutica\%20[Sicario\%20Inf ernal].PDF (último acceso el 10 de junio de 2017).

LOZANO, Andrea., "Lektá e incorporalidad: la estrategia estoica frente al problema del cambio". Revista de Filosofía de la Universidad de Costa Rica, XLVI (117-118), pp. 169-180. Costa Rica, 2008.

MILLS, Jon: "Philosophical Counseling as Psychotherapy: An Eclectic Approach", disponible on-line en http://npcassoc.org/docs/ijpp/mills.pdf (último acceso 10 de junio de 2017).

MORIN, Edgar, El método I: La naturaleza de la naturaleza, tr. Ana Sánchez, Cathedra: Madrid, 2001.

SCHUSTER, Shlomit C., Marinoff's Therapy: A Critique of His Books on Philosophical Practice, disponible en http://npcassoc.org/docs/ijpp/SchusterMarinoff.pdf (último acceso el 10 de junio de 2017). 